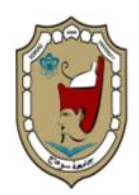

Sohag University

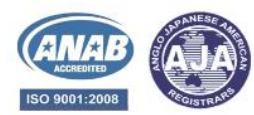

Sohag Medical Journal

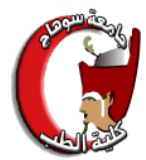

Faculty of Medicine

\title{
Stroke in young versus elderly clinical characteristic and in hospital mortality a retrospective cross- sectional study
}

\author{
Hazem Kamal Ibrahim, Mohamed Khodery, Hassan Mohamed Elnady.
}

Department of Neurology and psychological medicine, Sohag university, Egypt

\section{Background and purpose}

About 10-15\% of all ischemic strokes occur in young adults, limited researches have specifically addressed stroke in the young, also, the etiology of ischemic stroke in the young are heterogeneous and can be relatively uncommon the purpose is to identify different risk factors of stroke in young and elderly and predictors of in hospital mortality

patient and method: consecutive 197 patient with acute ischemic stroke admitted to neurology department, Sohag university hospital subdivided into two groups according to the age and the cut of point between young and elderly is 50-year, clinical characteristics, risk factors and hospital mortality was compared in both groups

Results: The prevalence of Rheumatic heart disease is common in ischemic stroke in young adult than elderly while hypertension is the most prevalence vascular risk factor, Charlson comorbidity index is independent predictor of hospital mortality of ischemic stroke in elderly

Conclusion: Rheumatic heart disease still prevalent in young adult in a sample of Egyptian population, hypertension is the most important modifiable risk factor Charlson comorbidity index and Scandinavian stroke scale on admission are predictors of hospital mortality in elderly and young adult respectively

Keywords: Rheumatic heart disease, stroke in young, hospital mortality

\section{List of abbreviation}

PFO; patent foramen oval, IHD; ischemic heart disease, RHD; rheumatic heart disease, mRS; modified Ranking Scale, SSS; Scandinavian stroke scale, CMI; Charlson Comorbidity Index.

\section{Introduction:}

Stroke is the disease of old age and about $10 \%$ of stroke patients are young, the incidence of ischemic stroke in young is increasing ${ }^{1}$, the causes of this increase is uncertain, stroke in young has a significantly higher risk of early death in comparing to early death in general populations

Traditional stroke risk factors are known, many studies for stroke in a young, large study found that prevalence of hypertension is $39 \%$, hyperlipidemia $60 \%$, and smoking $44 \%{ }^{3}$, Another study revealed a high prevalence of conventional stroke risk factors ${ }^{\varepsilon}$

Assessment of the patient with ischemic stroke at young age firstly need assessment like a stroke in the elderly furthermore need evaluation for other risk factors as cervical artery dissection, hypercoagulable state, patent foramen oval, vasculitis and hereditary blood disorders, dissection of arterial blood vessels is common it represents about $2 \%$ of ischemic stroke dissection on cervical arteries is either primary or 
secondary to trauma, and may be associated with connective tissue diseases like Marfan syndrome and Ehler Danlos syndrome type 4 and others ${ }^{5,6}$

The incidence of arterial dissection per year is 1.72 per 100,000 for carotid vessels while 0.97 per 100,000 for vertebral vessels ${ }^{7}$, the fifth decade is the highest incidence and about $10 \%$ of cases are intracranial, multiple vessels in about $16 \%$ of cases ${ }^{8}$ Recent analysis conclude that clinical characteristics, risk factors and also functional outcome are different in comparing internal carotid with vertebral dissection ${ }^{9,10}$, Dissection of the cervical artery may be due to intimate tear followed by intramural hematoma or primarily intramural hematoma without intimate tear $^{11}$ Superficial temporal artery wall abnormalities suggests that arteriopathy affecttion of adventitia and intima is important in the pathogenesis of the dissection ${ }^{12}$. Arterial dissection is multifactorial, dissection is associated with either major or minor trauma. or coughing or sneezing among other people ${ }^{13}$ this study aims to clarify the difference between stroke in young and elderly and predictors of in-hospital mortality.

\section{patient and methods}

a consecutive 197 patients admitted to the Department of Neurology, Sohag University Hospitals, were screened with an acute ischemic stroke (AIS) diagnosis between May 2012 and May 2014. Figure1 the eligibility criteria for involvement in the study is an acute ischemic stroke diagnosis admitted within the first 24 hours following the onset of the symptoms. Ischemic disorders incl- uding shock, renal failure, documented inflammatory or malignant disease were omitted if patients had a clinical record of the previous documentation. Young adult is less than 50 years according to international classification $^{24}$

\section{Ethical consideration}

The ethical committee of the Sohag Faculty of Medicine approved our study. all patients signed written consent. acute ischemic stroke was defined according to World Health Organization definition ${ }^{26}$, patient charts were abstracted for different variables, including age, sex, and vascular risk factors, and active smoking, the residence was defined as urban or rural. Charlson Comorbidity Index [CMI]. ${ }^{{ }^{5}}$ used for comorbidities in elderly group stroke severity (as measured by the Scandinavian Stroke Scale [SSS] on admission and modified Rankin Scale [mRS] at discharge.

statistical analysis

Analytical data have been analyzed for the Social Sciences Statistics Packages for the windows and by Graph Pad Prism 7.0 (Graph Pad Software Inc., La Jolla, California, USA). Continuous data as a mean \pm standard deviation, and categorical data as numbers and percentages were presented. The Student Ttest for the continuous data Chi-square test for categorical data carried out analyses of disparities between young and old stroke patients. Instead of a Pearson Chi square test, we used Fisher Exact test when the data is non-parametric. Statistically important $\mathrm{P}$ values less than or equal to 0.05 were considered. 


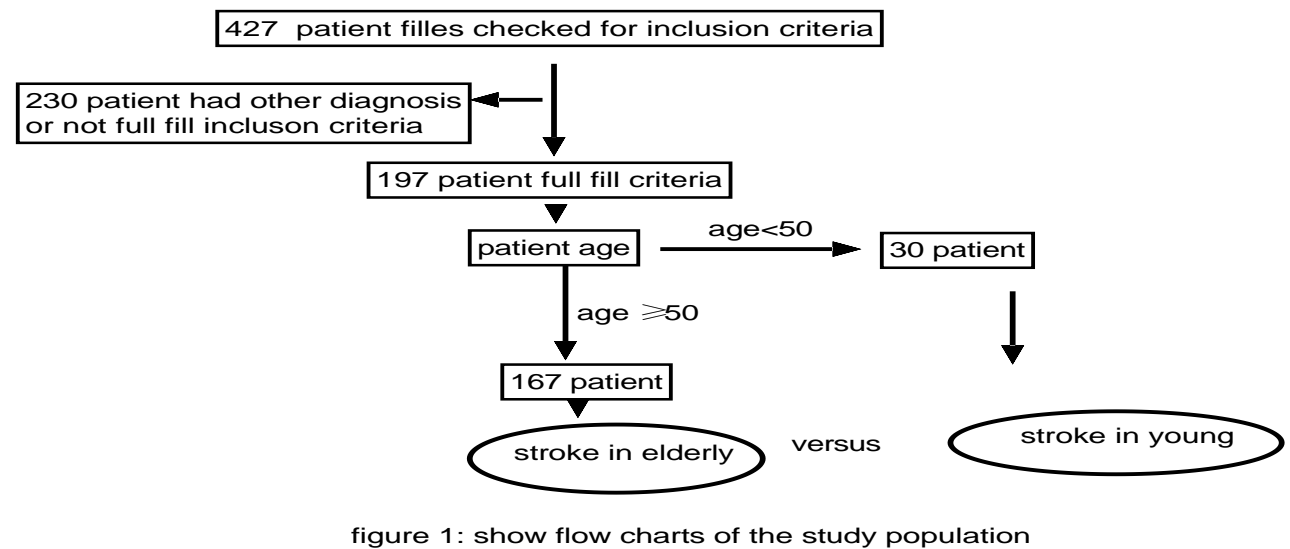

\section{Results}

The mean age of a young adult is $38 \pm 9.88$ and for elderly $65 \pm 9.3$, female is relatively common than male in both young and elderly and most of the cohort are from rural residence with no statistically significant difference History of old stroke or Transient Ischemic Attack is non significantly higher in elderly than young Regarding vascular risk factors, hypertension is statistically significantly higher in elderly than young $(\mathrm{p}$-value $=0.03$ ) Figure $2 \mathrm{~A}$ diabetes millets and IHD in nonsignificantly higher in elderly ( $\mathrm{p}$-value $=0.78)$ and $(0.92)$ respectively RHD is statistically significantly higher in young adult ( $\mathrm{p}$-value $=0.003$ ) Figure $2 \mathrm{~B}, \mathrm{CMI}$ is statistically significantly higher in elderly ( $\mathrm{p}$-value $\leq 0.001$ ) and SSS is statistically higher among young ( $\mathrm{p}$-value $=0.047)$ MRS is near significant higher in elderly ( $\mathrm{p}$-value $=0.063$ ) Table 1

\begin{tabular}{|c|c|c|c|}
\hline Variable & Young $(n=30)$ & Elderly $(n=167)$ & P value \\
\hline Age mean +SD & $38 \pm 9.88$ & $65 \pm 9.3$ & $\leq 0.001$ \\
\hline $\begin{array}{l}\text { Sex, Male,n }(\%) \\
\text { Female, n (\%) }\end{array}$ & $\begin{array}{l}10(5.1) \\
20(10.2)\end{array}$ & $\begin{array}{l}70(35.5) \\
97(49.2)\end{array}$ & 0.37 \\
\hline $\begin{array}{r}\text { residence, Urban, n (\%) } \\
\text { Rural, n (\%) }\end{array}$ & $\begin{array}{l}13(6.7) \\
17(8.8)\end{array}$ & $\begin{array}{l}65(33.7) \\
98(50.8)\end{array}$ & 0.72 \\
\hline Active smoking, n (\%) & $3(1.5)$ & 21(10.7) & 1 \\
\hline $\begin{array}{l}\text { History of stroke (\%) } \\
\text { History of TIA,n(\%) }\end{array}$ & $\begin{array}{l}5(2.5) \\
2(1)\end{array}$ & $\begin{array}{l}37(18.8) \\
13(6.6)\end{array}$ & $\begin{array}{l}0.49 \\
1\end{array}$ \\
\hline $\begin{array}{l}\text { Hypertensive, n (\%) } \\
\text { Diabetic, n (\%) } \\
\text { IHD,n(\%) } \\
\text { RHD,n(\%) }\end{array}$ & $\begin{array}{l}7(3.6) \\
4(2) \\
5(2.5) \\
3(1.5)\end{array}$ & $\begin{array}{l}74(37.6) \\
48(24.4) \\
29(14.7) \\
0(0)\end{array}$ & $\begin{array}{l}\mathbf{0 . 0 3} \\
0.78 \\
0.92 \\
\mathbf{0 . 0 0 3}\end{array}$ \\
\hline CMI & $2.4 \pm 0.5$ & $4.89 \pm 1.2$ & $\leq 0.001$ \\
\hline SSS & $39 \pm 19$ & $32 \pm 18$ & 0.047 \\
\hline mRS & $2.9 \pm .98$ & $3.6 \pm 1.76$ & 0.063 \\
\hline Died & $5(2.5)$ & $32(16.2)$ & 0.74 \\
\hline
\end{tabular}

Table 1: Clinical characteristics and risk factors of both groups.

IHD; ischemic heart disease, RHD; rheumatic heart disease, mRS; modified Ranking Scale, SSS; Scandinavian stroke scale, CMI; Charlson Comorbidity Index 


\begin{tabular}{|l|l|l|l|}
\hline \multicolumn{1}{|l|}{ Odd ratio } & CI & P value \\
\hline Univariate in young & 0.85 & $0.733-0.988$ & 0.034 \\
\hline SSS & 0.92 & $0.89-0.95$ & 0.000 \\
\hline Univariate in elderly & 1.96 & $1.33-2.88$ & 0.001 \\
\hline SSS & \multicolumn{4}{|l|}{$\mid$\begin{tabular}{ll}
$\mid$ \\
\hline CMI
\end{tabular} Multi variate logistic regression analysis of clinical predictors of mortality in elderly } \\
\hline SSS & 0.94 & $\mathbf{0 . 9 1 - 0 . 9 8}$ & 0.004 \\
\hline CMI & 1.7 & $1.08-2.7$ & 0.021 \\
\hline
\end{tabular}

Table2: Univariate and Multivariate logistic regression analysis of clinical predictors of hospital mortality in young and elderly.

SSS; Scandinavian stroke scale, CMI; Charlson Comorbidity Index

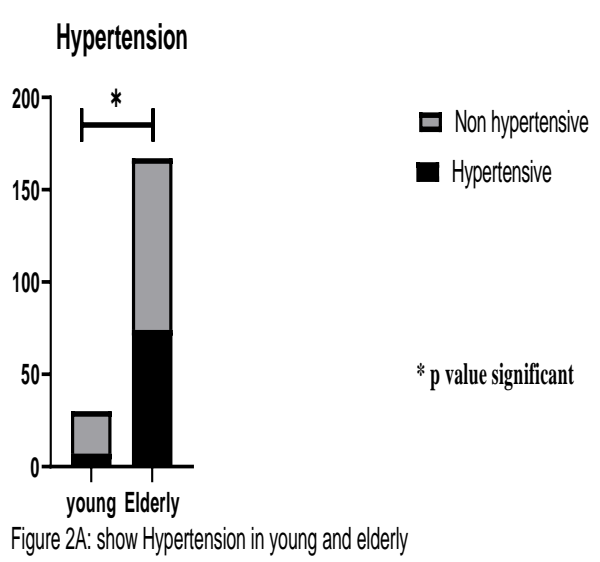

\section{Discussion}

Cardiac disease, hypertension, and diabetes mellitus are the most common risk factors among elderly people ${ }^{14}$. and that corresponds to our results

Another research identified hyperlipidemia then smoking, and finally hypertension $^{15}$ as the most common vascular risk factors. Another review article explains the increased risk of cerebral infarction in young adults with traditional vascular risk factors is noted, especially in developing states because of incre used smoking levels and urbanization, and this is not alien in our conclusion and this may be due to ethnic differ-ences in stroke risk factors as well. ${ }^{20}$ and the differences explained by the small number of adult patients of our cohort.
Rheumatic Heart disease

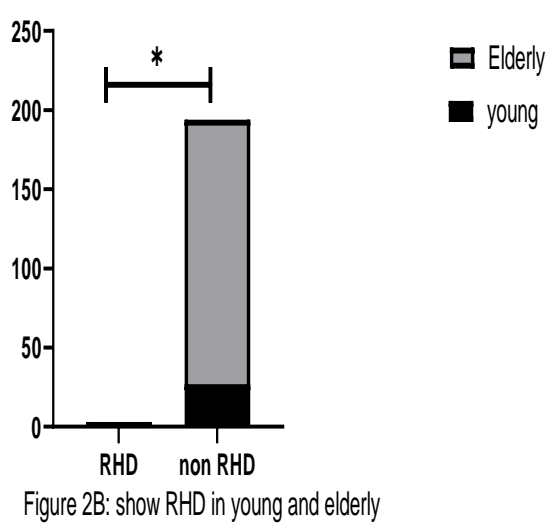

In another study by Putaala and colleague ${ }^{16}$, Current smoking (49\%), and hypertension $(36 \%)$ were the three most common risk factors ${ }^{16}$.and this also in line with our finding also common in $y$ oung stroke patients in the People's Republic of China and New Zealand were classical vascular risk factors, including hypertension, dyslipidemia and cigarette smoking ${ }^{17,18}$. And this not in line with our finding as we found Rheumatic heart diseases is statistically significant in young age groups and this can be due to prevalence of rheumatic heart disease in developing countries rather than other, Scandinavian stroke scale is a predictor of stroke mortality in both young and adult while Charlson comorbidity index is an independent 
predictor of hospital mortality in elderly this is in line with previous studies, ${ }^{19,20}$ a recent review article conclude that In the past, stroke in has been viewed as a disease with different risk factors and etiology and usually a better prognosis comparing to stroke in older patients. However, this view may be challenged. Traditional vascular risk factors in young adults with stroke have been somewhat neglected in the literature, which seems unjustified given their high prevalence $\mathrm{e}^{21,22}$

Limitation of the study the limitations of our study is the retrospective nature. Conclusion valvular heart disses is still an important etiology of stroke in young age in a sample of the upper Egyptian population, other vascular risk factors are common in also in both young and elderly population, hypertension is the commonest vascular risk factor of stroke in the elderly, admission Scandinavian stroke scale is a predictor of hospital mortality of stroke patient, Charlson comorbidity index is a clinical independent predictor of hospital mortality in elderly stroke patients.

$\begin{array}{ll}\text { Funding } & \text { None } \\ \text { Acknowledge } & \text { Not applicable } \\ \text { Conflict of interest } & \text { None }\end{array}$

\section{References}

1. Kissela BM, Khoury JC, Alwell K, et al. Age at a stroke: temporal trends in stroke incidence in a large, biracial population. 2012;79(17):1781Y1787.

2. Rutten-Jacobs LC, Arntz RM, Maaijwee NA, et al. Long-term mortality after stroke among adults aged 18 to 50 years. JAMA 2013;309(11):1136Y1144.

3. Putaala J, Metso AJ, Metso TM, et al. Analysis of 1008 consecutive patients aged 15 to 49 with first-ever ischemic stroke: the Helsinki young stroke registry.Stroke 2009;40(4):1195Y1203.

4. Ji R, Schwamm LH, Pervez MA, Singhal AB. Ischemic stroke and transient ischemic attack in young adults: risk factors, diagnostic yield, neuroimaging, and thrombolysis. JAMA Neurol 2013;70(1):51Y57.

5. Caplan LR, ed. Uncommon causes of stroke. 2nd edition. Cambridge, UK: Cambridge University Press, 2008.

6. Giroud M, Fayolle H, Andre' N, et al. Incidence of internal carotid artery dissection in the community of Dijon. $\mathbf{J}$ Neurol Neurosurg Psychiatry 1994;57(11):1443.

7. Lee VH, Brown RD, Mandrekar JN, Mokri B. Incidence and outcome of cervical artery dissection: a populationbased study. Neurology 2006;67(10):1809Y1812.

8. Debette S, Leys D. Cervical-artery dissections: predisposing factors, diagnosis, and outcome. Lancet Neurol 2009;8(7):668Y678.

9. von Babo M, De Marchis GM, Sarikaya $\mathrm{H}$, et al. Differences and similarities between spontaneous dissections of the internal carotid artery and the vertebral artery. Stroke 2013;44(6):1537Y1542.

10.Debette S, Grond-Ginsbach C, Bodenant M, et al. Differential features of carotid and vertebral artery dissections: the CADISP study. Neurology 2011;77(12):1174Y1181.

11.Schievink WI. Spontaneous dissection of the carotid and vertebral arteries. N Engl J Med 2001;344(12):898Y906.

12. Vo" lker W, Dittrich R, Grewe S, et al. The outer arterial wall layers are primarily affected in spontaneous cervical artery dissection. Neurology 2011;76(17): 1463Y1471.

13.Engelter ST, Grond-Ginsbach C, Metso TM, et al. Cervical artery dissection: trauma and other potential mechanical trigger events. Neurology 2013;80(21):1950Y1957.

14. Smajlović DŽ, Salihović D, Ibrahimagić OĆ, Sinanović O. Characteristics of stroke in young adults in Tuzla Canton, Bosnia, and Herzegovina. Coll Antropol. 2013;

15.Putaala J, Metso AJ, Metso TM, et al. Analysis of 1008 consecutive patients aged 15 to 49 with first-ever ischemic stroke: the Helsinki Young Stroke Registry. Stroke. 2009; 40:1195-1203.

16.Putaala J, Yesilot N, Waje-Andreassen $\mathrm{U}$, et al. Demographic and geographic vascular risk factor differences in 
European young adults with ischemic stroke: the 15 Cities Young Stroke Study. Stroke. 2012; 43:2624-2630.

17.Zhang YN, He L. Risk factors study of ischemic stroke in young adults in Southwest China. Sichuan Da Xue Xue Bao Yi Xue Ban. 2012; 43:553557. Chinese.

18.Wu TY, Kumar A, Wong EH. Young ischaemic stroke in South Auckland: a hospital-based study. N Z Med J. 2012; 125:47-56.

19. Tessier A, Finch L, Daskalopoulou SS, Mayo NE. Validation of the Charlson Comorbidity Index for predicting the functional outcome of stroke. Arch Phys Med Rehabil 2008; 89:1276-83

20.Pedro EnriqueJiménez, Caballero,FidelLópez EspuelaBP, RNJuan CarlosPortilla CuencaJosé, MaríaRamírez ,Moreno,IgnacioCasado Naranjo, Charlson Comorbidity Index in Ischemic Stroke and Intracerebral Hemorrhage as Predictor of Mortality and Functional Outcome after 6 Months, j.jstrokecerebrovasdis.2012.11.014

21.M. Brainin, Y. Teuschl, and L. Kalra, "Acute treatment and long-term management of stroke in developing countries," Lancet Neurology, vol. 6, no. 6, pp. 553-561, 2007.View at: Publisher Site | Google Scholar
22.Maaijwee, N. A. M. M. et al., Ischaemic stroke in young adults: risk factors and long-term consequences at. Rev. Neurol. 10, 315-325 (2014);

23.Singhal, A. B. et al. Recognition and management of stroke in young adults and adolescents. Neurology 81, 10891097 (2013).

24.Waje-Andreassen U, Thomassen L, Jusufovic M, et al. Ischaemic stroke at a young age is a serious event--final results of a population-based long-term follow-up in Western Norway. Eur J Neurol. 2013;20(5):818-823.

25.Charlson ME, Pompei P, Ales KL, MacKenzie CR. A new method of classifying prognostic comorbidity in longitudinal studies: development and validation. J Chronic Dis. 1987; 40:373-383.

26. Aho $K$, Harmsen $P$, Hatano $S$, Marquardsen J, Smirnov VE and Strasser T. Cerebrovascular disease in the community: results of a WHO collaborative study. Bull World Health Organ 1980; 58: 113-130. 